\title{
CLOUD COMPUTING \\ AS A KEY ENABLER FOR TECH START-UPS ACROSS ASIA AND THE PACIFIC
}

Thomas Abell, Arndt Husar, and Lim May-Ann

NO. 79

July 2021

\section{ADB SUSTAINABLE DEVELOPMENT WORKING PAPER SERIES}





\section{ADB Sustainable Development Working Paper Series}

\section{Cloud Computing as a Key Enabler for Tech Start-Ups across Asia and the Pacific}

Thomas Abell, Arndt Husar, and Lim May-Ann

No. 79 | July 2021
Thomas Abell is the chief of the Digital Technology for Development Unit at the Asian Development Bank (ADB) that is tasked with facilitating the effective use of digital technology to improve development impact. He has over 30 years of professional experience in digital technology.

Arndt Husar is a senior public management specialist (digital transformation) in ADB's Digital Technology for Development Unit, where he facilitates the effective use of digital technology, advising ADB clients, regional departments, as well as sector and thematic groups.

Lim May-Ann is the executive director of the Asia Cloud Computing Association, and managing director of the technology research firm, TRPC Pte Ltd. She is a public policy professional, focusing on development, technology policy, and communications across Asia and the Pacific. 
(C) 2021 Asian Development Bank

6 ADB Avenue, Mandaluyong City, 1550 Metro Manila, Philippines

Tel +632 8632 4444; Fax +63286362444

www.adb.org

Some rights reserved. Published in 2021.

Publication Stock No. WPS210253-2

DOI: http://dx.doi.org/10.22617/WPS210253-2

The views expressed in this publication are those of the authors and do not necessarily reflect the views and policies of the Asian Development Bank (ADB) or its Board of Governors or the governments they represent.

ADB does not guarantee the accuracy of the data included in this publication and accepts no responsibility for any consequence of their use. The mention of specific companies or products of manufacturers does not imply that they are endorsed or recommended by ADB in preference to others of a similar nature that are not mentioned.

By making any designation of or reference to a particular territory or geographic area, or by using the term "country" in this document, $A D B$ does not intend to make any judgments as to the legal or other status of any territory or area.

This work is available under the Creative Commons Attribution 3.0 IGO license (CC BY 3.0 IGO)

https://creativecommons.org/licenses/by/3.0/igo/. By using the content of this publication, you agree to be bound by the terms of this license. For attribution, translations, adaptations, and permissions, please read the provisions and terms of use at https://www.adb.org/terms-use\#openaccess.

This CC license does not apply to non-ADB copyright materials in this publication. If the material is attributed to another source, please contact the copyright owner or publisher of that source for permission to reproduce it. ADB cannot be held liable for any claims that arise as a result of your use of the material.

Please contact pubsmarketing@adb.org if you have questions or comments with respect to content, or if you wish to obtain copyright permission for your intended use that does not fall within these terms, or for permission to use the ADB logo.

The ADB Sustainable Development Working Paper Series presents data, information, and/or findings from ongoing research and studies to encourage exchange of ideas and elicit comment and feedback about development issues in Asia and the Pacific. Since papers in this series are intended for quick and easy dissemination, the content may or may not be fully edited and may later be modified for final publication.

Corrigenda to ADB publications may be found at http://www.adb.org/publications/corrigenda.

Notes:

In this publication, “\$” refers to United States dollars. 


\section{CONTENTS}

Table and Figures

Acknowledgments

vii

Abbreviations

viii

Executive Summary

ix

$\begin{array}{ll}\text { I. Introduction } & 1\end{array}$

II. Benefits of Cloud Computing in Helping to Accelerate Start-Ups 2

III. Barriers to Cloud Computing Use in Start-Ups 9

IV. Recommendations: How Governments Can Support Their Start-Ups 13 with Conducive Policies

$\begin{array}{ll}\text { V. Conclusion } & 21\end{array}$

$\begin{array}{ll}\text { References } & 22\end{array}$ 


\section{TABLE AND FIGURES}

Table

Cost Comparison for Developing On-Premises Solution against Cloud Solution

\section{Figures}

$1 \quad$ What Is Cloud Computing?

5

2 Shared Responsibility Model 


\section{ACKNOWLEDGMENTS}

This paper was prepared as part of the implementation of the Asian Development Bank (ADB) regional technical assistance, Digital Development Facility for Asia and the Pacific, which is cofinanced by the Republic of Korea e-Asia and Knowledge Partnership Fund. Lim May-Ann, domain expert and consultant, ADB led the writing of the paper, with guidance from Thomas Abell, chief, Digital Technology for Development Unit, ADB Sustainable Development and Climate Change Department (SDCC); and Arndt Husar, senior public management specialist (digital transformation), Digital Technology for Development Unit, SDCC. Lisette Cipriano, senior digital technology specialist, ADB Finance Sector Group, provided case study insights. Samantha Brown, consultant, ADB copyedited the draft paper; Lawrence Casiraya, consultant, ADB proofread the draft paper; Ginojesu Pascua, consultant, ADB prepared the graphics work; and Jennifer Flint, consultant, ADB typeset the final publication. Laarni Zapanta-Tuazon, senior operations assistant, SDCC; and Carmela FernandoVillamar, digital technology officer, SDCC provided valuable administrative support.

The peer reviewers of this working paper were Shehara Viswanathan, technology leader and cloud advisor, Asia-Pacific, Japan, and the People's Republic of China, Cisco Systems; and Digbijoy Shukla, business development lead, Start-Up Ecosystem ASEAN, Amazon Web Services.

ADB greatly acknowledges all these contributions and would like to give special thanks to the Asia Cloud Computing Association and the Amazon Web Services Institute, which provided valuable feedback and inputs. 


\section{ABBREVIATIONS}

$\begin{array}{ll}\text { ADB } & \text { Asian Development Bank } \\ \text { AWS } & \text { Amazon Web Services } \\ \text { AI } & \text { artificial intelligence } \\ \text { BSP } & \text { Bangko Sentral ng Pilipinas (Central Bank of the Philippines) } \\ \text { COVID-19 } & \text { coronavirus disease } \\ \text { CSP } & \text { cloud service provider } \\ \text { ICT } & \text { information and communications technology } \\ \text { IT } & \text { information technology } \\ \text { MOU } & \text { memorandum of understanding } \\ \text { NBP } & \text { National Broadband Plan } \\ \text { PRC } & \text { People's Republic of China } \\ \text { SME } & \text { small and medium-sized enterprise } \\ \text { US } & \text { United States } \\ \text { UK } & \text { United Kingdom }\end{array}$




\section{EXECUTIVE SUMMARY}

The Asia and Pacific region is home to dynamic start-up ecosystems, with new enterprises that produce digital solutions for domestic, regional, and global markets serving a wide variety of businesses, public institutions, civil society, and consumers directly. The growth of the digital economy has accelerated in the context of the coronavirus disease (COVID-19) pandemic; but even before, its size has reached $\$ 100$ billion in Southeast Asia by 2020. 'The enhanced digital connectivity in Pacific island countries has significantly improved the competitiveness of businesses that are either digitally native (born digital) or adopting digital solutions to improve their services or products.

The success stories of technology start-ups are attracting investments and bringing cutting-edge technology to emerging markets, be it stories of adoption where digital solutions are contextualized to local needs, or as innovations that are entirely different, or even as "deep tech" solutions, which leverage the latest and greatest insights from research and science. Cloud-native start-ups offer opportunities for engineers to upskill and develop new technical proficiencies, exposing local talent pools to skills they might not develop through more traditional information technology (IT) experience. New business models, technology innovations, novel combinations of digital technologies, and international trade have provided opportunities for start-ups to introduce new solutions, win market share, and disrupt legacy businesses and industries.

The employment opportunities that start-ups generate, their drive for innovation, their impact on the competitiveness of more traditional economic sectors, and the impact they have on the emergence and growth of a digital economy cannot be understated. Start-ups are essential components of a thriving digital economy because they most effectively integrate leading talent and sources of capital, and they are driven by an urgency to succeed quickly-if they do not, they will try to more effectively deploy skills and resources. Governments in developing member countries of the Asian Development Bank (ADB) should establish or refine policies and mechanisms that foster vibrant start-up ecosystems. The competition for digital talent, founders, and investors is already well underway, but growing a pipeline of high-potential local start-ups and engaging regional and global leaders with attractive solutions need to be part of any digital economy strategy. Cloud computing is one of the foundational technologies and infrastructures requiring the attention of policy makers around the region, for whom this paper has been produced.

Start-ups of all shapes and sizes are building their solutions and platforms using cloud-computing technology and are integrating services provided by cloud-based companies. Flexible and easily scalable cloud services greatly enhance the typical innovation journey of start-ups, which includes prototyping, testing, iterating, and adjusting rapidly to customer needs. Since costly capital expenditure for hardware can be avoided, start-ups are able to do so cost effectively with a high degree of flexibility, characteristics that bode particularly well for early-stage start-ups. Growth-stage start-ups and later-stage scale-ups benefit from the ability to scale rapidly as their user base expands, and to handle peaks in demand. Startups that build on the proven technology stack of cloud services can focus on their core innovations, rather than reinventing the wheels of basic computing services.

Given that start-ups are often testing regulatory boundaries and challenging the status quo with their solutions and business models, they require an enabling environment. This includes conducive policies for infrastructure development and data governance, as well as supportive government institutions that foster their growth; understand their needs; and lend a hand with market access, financial incentives, or advisory services. This paper provides an overview of the opportunities and challenges involved and suggests how policy makers can help start-ups make the most of cloud-computing technologies.

Google, Temasek, and Bain \& Company. 2020.e-Conomy SEA 2020. 



\section{INTRODUCTION}

The rapid growth of entrepreneurial businesses and start-ups has been accelerated by technologies such as cloud computing. The private sector is galvanized by the possibility of being, or investing in, the next "unicorn" start-up; and the public sector is excited at the economic growth opportunities presented by technology. ${ }^{2}$ From a public policy perspective, technology start-ups (tech start-ups) are key drivers for the digital economy, which is playing an increasingly important role in Asia and the Pacific. In fact, some reports place 6 out of the world's top 11 start-up hubs in this region. ${ }^{3}$

There are no clear definitions of a tech start-up, although as starting point, it is commonly defined as "an organization formed to search for a repeatable and scalable business model," typically developed with a strong, central focus on technology, typically equity-funded, and started by a small group of founders. ${ }^{4}$ Another characteristic is that it tends to foster innovation based on a fast-paced business model of succeeding or failing quickly. This distinguishes venture capital-backed start-ups from traditional smalland medium-sized enterprises (SMEs) which tend to be more risk-averse in comparison, and may not be as driven to expand rapidly, given the difference in funding models. Start-ups play a key role in driving innovation by inspiring younger generations to pursue technology-focused careers or entrepreneurship. Tech start-ups typically represent a small segment when measured by employment or revenues, but they are critical enablers of digital transformation for developing countries.

Tech start-ups are also known for their nimble ability to adapt and pivot to suit various business environments and situations. In many developing countries, the ability of start-ups to leverage technology to address and solve some of society's most pressing problems has helped to bridge long-standing digital development gaps, such as challenges around access to finance, education, and health care in remote areas or underserved communities.

The disruption caused by the coronavirus disease (COVID-19) pandemic has brought new challenges and opportunities for start-ups. For example, lockdowns have severely curtailed businesses in sectors such as tourism, entertainment, and retail. Meanwhile, opportunities have been created in educational technology and remote health for start-ups to succeed. The economic outlook is seeing severely reduced consumer demand, limited revenue streams, and changes in investment decisions. Many workers are unable to return to their workplaces or restart their businesses due to movement restrictions. If the financing runway of a start-up is short, this might force them to reduce staff, pause operations, or even shut down without viable income paths. In a normal economic context, many start-ups fail; but in this environment, the chances of survival appear slimmer, and entrepreneurial efforts may prove to be challenging in the context of a recession.

Governments should ensure the healthy development of start-ups and create a conducive environment for start-ups to thrive. The pandemic has accelerated the transition to a digital economy and has increased citizens' reliance and acceptance of digital goods and services. It has forced digital transformation across all sectors, including government. Supporting agile and resilient tech start-ups will hugely benefit the overall economic recovery as they are catalysts for innovation and help accelerate the change of traditional companies and institutions. ${ }^{5}$

2 Investopedia (2020) defines "unicorn" as a term used in the venture capital industry to describe a privately held start-up company with a value of more than \$1 billion. Source: J. Chen. 2020. Unicorn. Investopedia. 31 March.

3 S. Abudheen. 2020. 6 of the World's Top 11 Startup Ecosystems are Now in Asia Pacific: Startup Genome Report 2020. E27. 26 June.

4 S. Blank. 2010. What's A Startup? First Principles. Steve Blank Blog. 25 January.

5 A. Husar. 2020. Fostering Resilient Start-Up Ecosystems in the New Normal. Development Asia. 4 September. 
Governments should ensure that start-ups in their countries can access, use, and deploy cloud-computing technologies, which most tech start-ups are reliant on. This report, therefore, looks at cloud computing as an essential building block for start-ups; details the benefits that cloud computing provides to startups; and examines the ways in which governments can develop cloud-friendly technology policies and investment strategies that enable, grow, and accelerate start-up businesses.

\section{BENEFITS OF CLOUD COMPUTING IN HELPING TO ACCELERATE START-UPS}

One of the most important drivers of a tech start-up's success is its ability to be an early adopter of emerging technologies, and its openness to building its business through innovative applications, both in service of existing enterprises and institutions, but also as a new market entrant. Cloud computing has emerged as a foundational infrastructure for building nimble, highly scalable, and digitally enabled firms. Multinational cloud platforms such as Alibaba Cloud, Amazon Web Services (AWS), Google Cloud, and Microsoft Azure, as well as domestic cloud computing companies across Asia and the Pacific, have ramped up their capacities and diversified their service offerings to support businesses, and have enabled a new generation of start-up companies.

There are key reasons why the combination of cloud and start-ups is so successful:

(i) Start-ups are lean organizations, and entrepreneurs just starting out are often cash-strapped and looking for efficient technology solutions. With cloud computing, global technology infrastructure is more cost-effective than traditional information and communication technology (ICT) infrastructure. Illustrating the potential cost savings to start-ups, venture capitalist Marc Andreessen said that cloud technology helped to lower the cost of running a basic internet application from about $\$ 150,000$ per month in the year 2020 to $\$ 1,500$ per month in 2014-a 100 times difference. $^{6}$

(ii) Start-ups often grow in spurts, capitalizing on opportunities such as an injection of venture capital funds, or after a strategic hire joins the team. The elasticity of cloud computing with a "pay-as-you go" and "pay-as-you-grow" operational strategy allows start-ups to provision the number of resources that they need, rather than over-provision their IT resources to ensure that they have enough capacity to handle their business operations at the peak level of activity.

This elasticity of the cloud reduces start-ups' costs and improves their ability to meet their growth demands. It de-risks the start-up growth process and ensures a start-up can control its upfront costs, as it does not need to invest heavily in anticipation of future demand.

Both the scalable nature of cloud computing and the reach of the internet enable start-ups to go global in minutes. This scalability is essential to "hypergrowth" start-ups as they grow and expand into new regions around the world. Conversely, cloud computing also allows for greater resilience in the face of unexpected challenges or rapidly changing business environments.

6 D. Bloomquist. 2014. Disrupting the Traditional VC Model: VC Adaptations for Seed Investments. Kauffman Fellows. 11 June. 
(iii) Start-ups often take on large entrepreneurial risk, which can be reduced on a technological front with cloud computing. This is because the self-provisioning nature of cloud computing allows for low-cost experimentation-no capital expenditure is needed to run proof-ofconcept projects, as servers may be purchased and deployed in minutes. These can also be scaled down if the experiment does not work.

(iv) Outsourcing the management and updating of technology infrastructure to cloud service providers also allows start-ups to focus their attention and energies on a higher level of innovation, devoted to building their business and key products. This also means that startups will always have on-demand access to the latest advanced technologies such as artificial intelligence, machine learning, and data analytics, which start-ups can use to build new products and further innovate.

This section delves deeper into how cloud computing helps start-ups and provides some examples of start-ups that have benefited from using cloud-computing technology.

\section{A. Cloud Infrastructure is More Cost Effective than Traditional Technology Infrastructure}

For cost-conscious start-ups, large upfront spending on on-premises ICT infrastructure, such as servers and networking equipment, and maintaining skilled staff needed for its operation can bog down their ability to focus on their core products or services. The table below provides an overview of the traditional cost categories for developing an on-premises solution versus moving to the cloud.

Table: Cost Comparison for Developing On-Premises Solution against Cloud Solution

\begin{tabular}{|c|c|c|}
\hline Category & On-Premises Solution & Cloud Solution \\
\hline \multirow{3}{*}{ Set-up costs } & Location costs for locating data center and server equipment & \multirow{4}{*}{$\begin{array}{l}\text { Hosted in the cloud and delivery over } \\
\text { the internet means no realty, set-up, and } \\
\text { maintenance costs, as these are in effect } \\
\text { "rented" from the cloud service provider. } \\
\text { These do not appear in cloud costings, } \\
\text { as these would be considered within the } \\
\text { cloud charges. }\end{array}$} \\
\hline & $\begin{array}{l}\text { Purchasing bare-metal racks, servers, networking, load } \\
\text { balancers, initial software purchase and licensing, wiring, } \\
\text { power management such as universal power supply and surge } \\
\text { protectors, cooling equipment, with capital expenditure to be } \\
\text { amortized over the years }\end{array}$ & \\
\hline & $\begin{array}{l}\text { Set-up and development of initial server architecture(s), } \\
\text { networking between other data centers }\end{array}$ & \\
\hline $\begin{array}{l}\text { Maintenance } \\
\text { costs }\end{array}$ & $\begin{array}{l}\text { Maintenance of physical data center, managing upgrades and } \\
\text { updates to the physical and virtual systems (e.g., upgrading } \\
\text { storage and security patches), management of compliance and } \\
\text { audits of the IT environment }\end{array}$ & \\
\hline
\end{tabular}

IT - information technology.

Source: Author.

\section{Cloud enables a pay-as-you go and pay-as-you-grow investment strategy.}

Prior to cloud computing, companies had to buy on-premises hardware to build their own data centers before they could develop, test, and successfully launch new digital products or services. Today, cloud platforms enable start-ups of any size to store, manage, process data, and use programs through a webbased interface. They also enable start-ups to build services on shared infrastructure and platforms through: (i) the ability to size and scale their technology infrastructure to suit their specific needs at a 
particular moment, via tools like data center provisioning calculators; and (ii) the ability to pay only the fees for the capacity that they use. This reduces costs and can help start-ups stay afloat in competitive business environments. ${ }^{7}$

For example, Indonesia's bill payments start-up, Ayopop, was able to control costs using its cloudcomputing provider's automated services, so that only two engineers were needed to maintain the infrastructure, even as operations expanded. ${ }^{8}$

The Republic of Korea's Kmong was founded in 2012 as a platform to connect buyers and sellers of freelance services. ${ }^{9}$ Built on cloud-computing infrastructure, Kmong has grown to become the Republic of Korea's first business services marketplace, with 170,000 registered experts in 11 categories, and with more than 1 million transactions as of 2019.

Conversely, using cloud computing eliminates the need for upfront investment as infrastructure capacity for data storage and processing no longer needs to be built in advance, but can be scaled to meet demand, as needed.

For example, cashback rewards platform, ShopBack, which was launched in Singapore and is now expanding across Asia and the Pacific region, reduced its server infrastructure costs by $60 \%$ using cloud technologies that allowed the company to scale resources depending on demand. ${ }^{10}$

\section{Cloud computing reduces entrepreneurial risk.}

The flexibility of cloud infrastructure to scale up or down also enables start-ups to take more risks with testing new product ideas in the market because the upfront investment required to prove a new idea is reduced.

Cost savings from using cloud further allow start-ups to use their limited financial resources where it counts most, such as investing in geographic expansion, user acquisition, or innovative product development.

For example, using cloud computing, Taipei,China-based Ucarer developed an app-based service that the elderly can use to book appointments with registered caregivers in the local community. By building on the cloud, Ucarer's ICT infrastructure costs were reduced by about $30 \%$, and $97 \%$ of the workload associated with operation and maintenance tasks was eliminated, which allowed the company to focus on product development. ${ }^{11}$

\section{B. Scalable Cloud Infrastructure is Nimbler and More Efficient than Traditional Infrastructure}

Using cloud-computing infrastructure, such as infrastructure-as-a-service, platform-as-a-service, and software-as-a-service offerings (Figure 1), allows start-ups to establish fast, reliable, and efficient

\footnotetext{
For example: Schneider Electric. Data Center Capital Cost Calculator. https://www.se.com/ww/en/work/solutions/ system/s1/data-center-and-network-systems/trade-off-tools/data-center-capital-cost-calculator/; and Expedient. Data Center Build vs Buy Calculator. https://expedient.com/knowledgebase/tools-and-calculators/data-center-build-vs-buycalculator/

8 Amazon Web Services (AWS). 2020. Ayopop Makes Bill Payment Easy with API on AWS. Amazon Solutions.

9 AWS. n.d. Kmong Achieves 30\% Higher Conversion with AWS. Amazon Solutions.

10 AWS. 2020. ShopBack Cuts Infrastructure Costs by 60\% with Amazon EC2 Spot Instances. Amazon Solutions.

11 AWS. 2017. Ucarer Case Study. Amazon Solutions.
} 


\section{Figure 1: What Is Cloud Computing?}

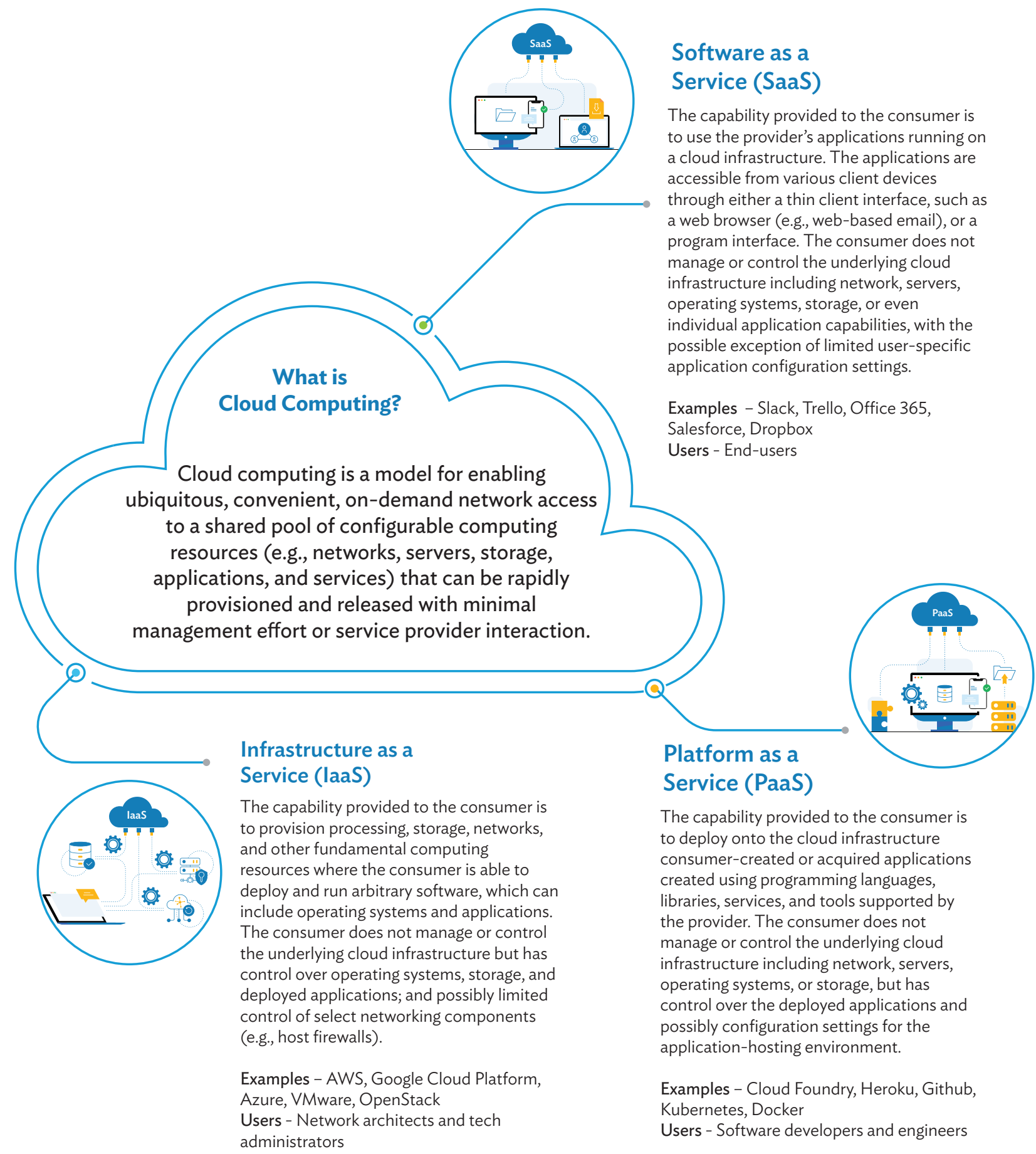

Source: Adapted from P. Mell and T. Grance. 2011. The National Institute of Standards and Technology Definition of Cloud Computing: Recommendations. 
foundations on which to develop their products. The scalability of cloud services means that startups can be agile and responsive to better meet customer demands and market needs quickly and cost efficiently, which improves their responsiveness and reliability.

Indonesian e-commerce unicorn Tokopedia improved platform uptime and reliability and created a more seamless experience for customers by using cloud technology. ${ }^{12}$ The company was able to adjust its IT operations after launching services on two public cloud servers located in Singapore and is now working to consolidate its IT infrastructure in Indonesia, its primary market.

Indonesian unicorn Traveloka, an online travel services firm, scaled its product delivery using cloud computing. ${ }^{13}$ Traveloka initially used cloud computing to ensure reliability and scalability during the early growth phase of the business. As the company became more successful, Traveloka used the flexibility of cloud computing to resolve issues such as rebalancing database nodes, memory limitations, and debugging user event clusters. The shift to cloud computing further resolved other issues including enabling low-latency, real-time messaging to manage user event data, switching to a cloud-based data flow process to manage streamed data to resolve memory limitations, and rebalancing data storage requirements with scalable cloud infrastructure. ${ }^{14}$

iFlix, a video-on-demand subscription start-up from Malaysia, was able to scale up quickly in response to strong market demand with the help of cloud services. ${ }^{15}$ It continues to run a successful video-ondemand business thanks to the ability to flexibly adjust its computing power to user demand.

Cloud computing's scalability has played a key role in allowing start-ups to expand while maintaining product quality, which is key to keeping customers in an increasingly competitive market.

Hong Kong, China e-restaurant system PinMe employed cloud technology to maintain high levels of computing capabilities to ensure that the in-app ordering experience would remain flawless and with low loading times for customers, even as the business expanded. Specifically, cloud-computing technology was key in providing scalability and resilience during lunch-hour traffic spikes. ${ }^{16}$

Leading games start-up in India, Games24x7, migrated their gaming systems to the cloud to better manage customer-driven usage spikes, while maintaining low latency to avoid negatively impacting the user experience given fluctuations in data transmission quality. ${ }^{17}$

Ultimately, having reliable cloud infrastructure allows start-ups to focus less on the operations and maintenance of ICT infrastructures and prioritize other areas.

Indonesian medical technology start-up Halodoc, which connects patients to doctors and delivers medication, leveraged cloud to improve latency and customer experience allowing the company to improve time-to-market by $30 \% .^{18}$

12 Tech in Asia ID. 2019. How Tokopedia Guarantees its Platform Uptime. Youtube. 9 December; Alibaba Cloud. n.d. Tokopedia. Alibaba Customers; and Google. n.d. Traveloka: Turns to Google Cloud Platform for Powerful Big Data Analytics. Google Cloud.

13 Tech in Asia ID. 2019. How Cloud Computing Helps Traveloka Scale its Product Delivery. Youtube. 25 November.

14 In computing, "latency" describes some type of delay. It typically refers to delays in transmitting or processing data. Source: Tech Terms. 2017. Latency. 3 March.

15 AWS. 2015. iFlix Case Study. Amazon Solutions.

16 Alibaba Cloud. n.d. PinMe. Alibaba Customers.

17 AWS. 2020. Games24x7 Uses Machine Learning on AWS to Personalize the Gaming User Experience. Amazon Solutions.

18 AWS. 2018. Halodoc Reduces Time-to-Market by 30\% Using AWS. Amazon Solutions. 


\section{Cloud Computing Allows for Greater Resilience in the Face of Unexpected Business Environments}

The ability for cloud infrastructure to provide back-up systems ("failover") in the case of unexpected situations, such as disasters triggered by natural hazards, improves start-up resilience. Using cloud computing ensures that companies can ensure that business continuity plans are augmented with a strong data storage and retrieval policy.

With about 100 stores, Chai Point is India's largest organized tea retailer. Using cloud computing has enabled the company to avoid any outages that would affect a range of business-critical systems, including a cloud-based enterprise resource planning system that integrates billing and supply chain activities and enables real-time monitoring of its retail stores. ${ }^{19}$

The qualities associated with cloud infrastructure have also helped start-ups address challenges from the COVID-19 pandemic, including lockdowns, and help accelerate response times.

Malaysia-based StoreHub, a food and beverage business management app, built home-delivery capabilities for its StoreHub ecosystem through its Beep Delivery mobile app in 48 hours using cloud computing to address the effect of Malaysia's movement control order on food and beverage vendors. ${ }^{20}$

India start-up inVOID deploys artificial intelligence-supported digital know-your-customer capabilities to increase remote access to finance, which was particularly useful in 2020 given COVID-19 movement restrictions ${ }^{21}{ }^{21}$ VOID was one of the first cloud-based mobile apps in India that allowed citizens to use video-based means to establish their identity and open a bank account. Since the start of 2020, the company has seen $250 \%$ growth in its revenue, and conducts more than 15,000 digital know-yourcustomer processes a day across India.

\section{Variety of Cloud Services Enable New On-Demand Business Services to be Created, Rolled Out, and Delivered}

Another reason that cloud platforms are critical to the success of start-ups is their provision of cloud-based business services. Every start-up needs basic services like accounting, human resource management and development, customer relations, marketing, communications, and legal services. Before cloud platforms became available, a start-up might have needed to build these business management capabilities themselves or outsource them to different vendors. Today, many platforms offer a multitude of software-as-a-service solutions via "cloud marketplaces," allowing businesses and individuals to build support systems according to their needs.

In addition, technical bridges are often available, meaning that data and processes housed on non-cloud legacy systems can be imported (also known as "lift and shift" or "rehost") into the cloud-computing systems. This reduces the burden of having to build a new system from scratch. As a result, start-ups have not only become producers of cloud solutions, but also consumers themselves.

Indonesian start-up N-Frnds is an ordering and accounting platform designed for retailers who may not necessarily have internet access. The company's platform uses a cloud-based messaging and work

19 AWS. 2017. Chai Point Scales to Support the Sale of 150,000 Cups of Chai Daily with AWS. Amazon Solutions.

20 AWS. 2020. StoreHub Helps Food and Beverage Businesses in Malaysia Overcome Lockdowns. Amazon Solutions.

21 AWS. 2020. inVOID Deploys its Verification Products Four Times Faster with the Help of AWS Managed Services. Amazon Solutions. 
management technology as the foundation for its service, which is accessible via both smartphone and landline. ${ }^{22} \mathrm{~N}$-Frnds is an example of how a cloud-based company builds cloud services for other companies.

\section{E. Cloud Technology Enables New Products Built on Advanced Technologies Such as Artificial Intelligence, Machine Learning, and Data Analytics}

Newer technologies such as artificial intelligence (AI), machine learning, and data analytics are being built and developed on cloud-computing technologies. In many instances, these are available ondemand, i.e., start-ups may not necessarily need to pay for these until they are required, if at all .

In many instances, these new technologies are natively available on the cloud, making it a natural "first stop" for start-ups when building out new products and services, thereby creating a new generation of "born-in-the-cloud" start-up companies.

Language Al start-up, Kata.ai, based in Indonesia, uses cloud infrastructure to support the development of its natural language-processing Al platform to master hundreds of Indonesian languages. Kata.ai's technology powers virtual assistants that help companies, such as banks or telephone service providers, communicate with customers or target certain audiences for marketing. ${ }^{23}$

Filipino start-up AdMov uses cloud-based Al technology to develop advertising solutions that use facial recognition to target ads to customers using ride-hailing services. Customizing ads allows AdMov's clients to be more efficient with their spending. ${ }^{24}$

Agrostar is an agriculture technology start-up from India. It uses a cloud platform to run a multilingual mobile app that connects farmers to knowledge resources. The company is also developing cloud-based machine learning components to help speed up crop blight diagnosis. ${ }^{25}$

Singsound is an app from the People's Republic of China (PRC). It uses its cloud provider's AI platform to process speaking and writing tests for up to 3 million students every day who attend more than 300 separate educational institutions. Cloud-computing infrastructure helps the company by allocating increased computing resources to manage excess traffic during school hours and large-scale tests. ${ }^{26}$

Uranbase, a start-up from the Republic of Korea, runs its 3D products and spatial data platform company on cloud computing. This takes advantage of the container-based environment ${ }^{27}$ and serverless architecture $^{28}$ to host the company's 3D and virtual reality needs. ${ }^{29}$

22 Microsoft. 2019. Startup Uses Microsoft Kaizala to Empower Indonesian Retailers to Achieve More. Microsoft Customer Stories. 6 November.

23 Google. n.d. Kata.ai: Creating Natural Language Processing Solutions to Serve 200 million+ Indonesians. Google Cloud Customers.

24 Microsoft. 2020. Tech Startup Uses Azure Cognitive Services to Improve Advertising for Local Businesses. Microsoft Customer Stories. 10 August.

25 Google. n.d. AgroStar: Small Farms in India Getting Big Help from the Cloud. Google Cloud Customers.

26 AWS. 2020. Singsound Turns to AWS to Handle Workload Spikes. Amazon Solutions.

27 A container is a standard unit of software that packages up code and all its dependencies, so the application runs quickly and reliably from one computing environment to another. Source: Docker. What is a Container?

28 A serverless architecture is a way to build and run applications and services without having to manage infrastructure. The application still runs on servers, but all the server management is done by the cloud service provider. The user no longer has provision, scale, and maintain servers to run its applications, databases, and storage systems. Source: AWS. Building Applications with Serverless Architectures.

29 AWS. n.d. Urbanbase Launches Services 20x Faster with AWS. Amazon Solutions. 
Pakistan start-up Botsify builds Al chatbots for social media and website customer support. Their system, built on cloud infrastructure, provides customers with the ability to train their chatbot, interact with clients, and/or integrate with other services. With cloud-computing technology, this start-up manages half a million chatbot requests daily. ${ }^{30}$

\section{BARRIERS TO CLOUD COMPUTING USE IN START-UPS}

While many start-ups employ cloud technology to help them build their businesses, barriers remain. This section reviews several core challenges that start-ups face when considering migrating their operations to a cloud environment.

\section{A. Lack of Connectivity and Network Infrastructure}

From a broader perspective, developing markets may lack the connectivity infrastructure needed as a foundation for cloud, as well as broader ICT usage. This is not only in terms of internet access, but also in reliability of the connection, speed, and affordability so that the internet is accessible to start-ups that are in the initial phases of operation, but also to potential customers looking to use the innovative solutions offered by these new ventures.

Cloud computing requires some basic network connectivity in a country to enable its full benefits, as a large amount of the big data, analytics, and processing is done via the internet, making it critical for data to be transmitted, and requiring a stable internet connection for data to be uploaded. The Asia Cloud Computing Association's Cloud Readiness Index 2020 breaks this down into three core infrastructural requirements:

(i) International connectivity in terms of the total amount of bandwidth that has been connected into the country.

(ii) Domestic broadband quality in terms of the average speed of connections citizens and businesses can expect from local connections.

(iii) The stability and sustainability of the power grid to reasonably service the related infrastructure. ${ }^{31}$

Often, while major cities may have internet access, tertiary cities and rural areas may be unserved or underserved, making digital services such as cloud tools difficult to access. Developing markets may also lack the necessary grid infrastructure, such as stable electricity supply, which is needed to help promote the usage of ICT equipment. Having digital connectivity and electricity supply in place are basic infrastructure that set the stage at a foundational level for cloud adoption.

\section{B. Restrictive Policy Environment}

Regulatory frameworks addressing technology usage are relatively new, therefore not all countries may have rules in place that can help guide the utilization of cloud solutions. These include regulations setting

AWS. n.d. Botsify Enhances Customer Experience with AWS. Amazon Solutions.

31 Asia Cloud Computing Association. 2020. Cloud Readiness Index 2020. 
expectations about how issues such as data privacy and cybersecurity should be handled, especially in the context of cross-border data transfers.

For start-ups in highly regulated service sectors such as health care and finance, ambiguous regulations or non-existent guidance around cloud usage can create confusion as to whether the use of cloud services is even permitted. This can leave start-ups deferring to on-premises solutions, which results in higher costs and decreased efficiency in comparison to the cloud.

Furthermore, even for those countries that do have cloud-related regulations, there may still be limited understanding of what differentiates cloud infrastructure from traditional on-premises infrastructure; what the implications are for various aspects of an outsourcing arrangement and contractual relationships; what shared responsibility is; and implications on security controls and audits, and other aspects and accountability mechanisms that exist in a contractor-vendor relationship. This has resulted in stilted policies imposing data localization and limiting cross-border data flows. Such policies prevent companies from using cloud services provided by hyperscale cloud service providers (CSPs), which may not have servers located within the borders of a specific jurisdiction-a common situation in Asia and the Pacific. In addition to preventing cloud usage for start-ups that are looking to service a domestic market, restrictions on cross-border data transfer can hinder the international expansion of start-ups.

\section{Lack of Familiarity with Cloud Solutions}

Although cloud technology has become ubiquitous among tech start-ups, a lack of familiarity with different CSPs and their respective solutions remains a barrier for adoption, particularly in developing markets where there may not be a high level of overall awareness.

This lack of familiarity with cloud solutions may also extend to misunderstanding basic tenets of cloud computing's "shared responsibility model," where the responsibility for using and maintaining the cloud resources are shared between both the client and the CSP.

\section{Shared Responsibility Model}

The widely used shared responsibility model in Figure 2 illustrates where the split in responsibilities lies when companies move to the cloud. A safe and secure system is where:

(i) the CSP is responsible for the security of the cloud, including protecting the hardware, software, networking equipment, and facilities; and

(ii) the customer is responsible for the configuration of security in the cloud, including how they manage data, classify assets, and use the appropriate tools to apply appropriate permissions for storing and retrieving data. ${ }^{32}$

For example, a CSP would be responsible for ensuring that the cloud services have security measures available and in place, such as putting in user-access passwords as a compulsory default setting for their cloud services - thus, ensuring that there is security of the cloud. The customer of the cloud is responsible for ensuring that they select a strong password, and that they continue to ensure their users do not share the password with other staff members - thus, ensuring security in the cloud.

The lack of familiarity with such a model can create difficulties for start-ups appreciating the extent to which they themselves control their data and its security on shared cloud infrastructure.

32 AWS. Shared Responsibility Model. https://aws.amazon.com/compliance/shared-responsibility-model/ 


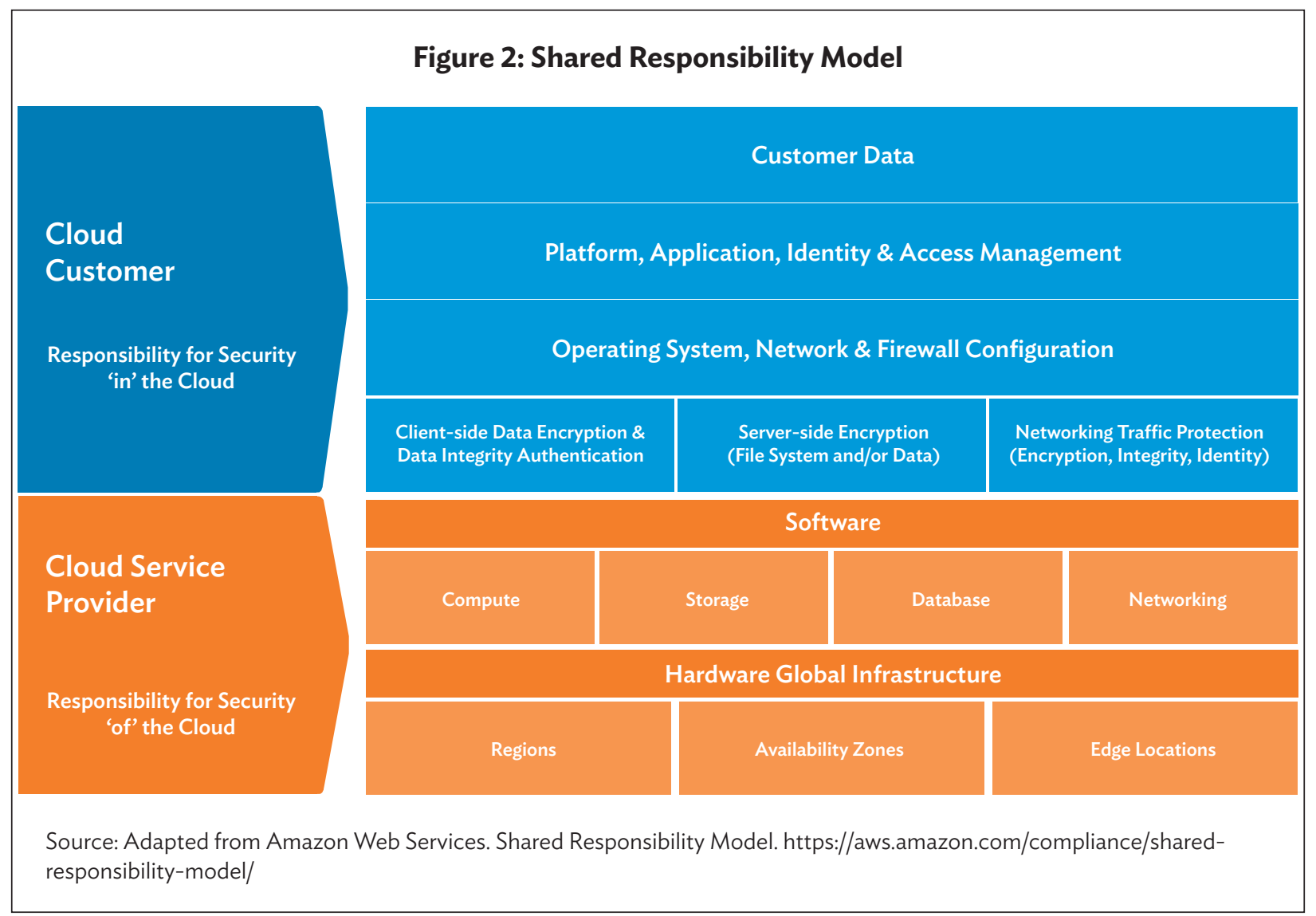

Another corollary to the problem of start-ups' lack of familiarity with cloud solutions is that CSPs are constantly improving and increasing their own service offerings to provide support for newer technologies, such as Al, machine learning, and data analytics. However, start-ups may be using only limited functionalities or configurations that do not fully deploy innovative new features. As start-ups focus on their business development, they may not be aware of the extent to which new cloud solutions may be able to help them innovate and stay ahead of the curve. This is where CSP partnerships with government may be able to assist, by facilitating consistent technology updates from CSPs to start-ups, and raising the general level of awareness among start-ups.

For example, cloud providers would be able to help secure start-ups' workloads and applications in the cloud through providing them with the following capabilities immediately: ${ }^{33}$

- data protection;

- identity and access management;

- infrastructure protection;

- threat detection and continuous monitoring; and

- compliance and data privacy.

This helps start-ups increase their ability to manage and control their information systems from the start of the business.

33 An example is the security offering from AWS. Security, Identity, and Compliance on AWS. https://aws.amazon.com/ products/security/ 


\section{Cloud Credits and Trials}

In many instances, CSPs have been very supportive of start-ups and have developed many programs that are targeted at this specific market segment. Some offerings are tailored specifically to subsegments of this market, including programs that differentiate between self-funded and funded start-ups, or startups that are in specific geographies.

The offerings available demonstrate that CSPs have worked to ensure that start-ups and companies looking to move to the cloud have a positive experience. For example:

(i) AWS has an Activate program ${ }^{34}$ for self-funded and funded start-ups, and in 2020, created an Activate Founders ${ }^{35}$ package, which is specially designed for bootstrapped start-ups to apply for up to $\$ 1,000$ in cloud credits, valid for 2 years, with 1 year of technical support. Funded and self-funded start-ups are eligible for up to $\$ 100,000$ in cloud credits if they partner with AWS Activate providers to build their business. ${ }^{36}$

(ii) Google Cloud Platform provides a 90-day free trial with $\$ 300$ credit, and there is a freetier resource allowance by which start-ups may continue to assess the suitability of services available for their business. ${ }^{37}$ Google also has a specific focus on start-ups with their Google for Start-Ups program, which offers cloud and business development tools, an accelerator program, a community, and mentorship for start-ups who get involved. ${ }^{38}$

(iii) Microsoft runs a Microsoft for Start-Ups global program focused on business-to-business start-ups, with various trials available to meet the different business needs of start-ups, which they match according to product market fit. This breaks down the needs of start-ups and matches their job functions to the cloud offerings available on Microsoft. ${ }^{39}$ For example, they have programs for cloud technology teams, providing up to $\$ 120,000$ free Azure cloud credits for 2 years, with Microsoft Power Platform, Office 365, and Dynamics 365 available. There are other programs for developers, who get a trial Visual Studio Enterprise account; or technical support teams, who get Azure Basic Support; or business enablement teams, who get access to the Microsoft Partner Network.

(iv) Huawei runs an SMEs \& Start-Ups program which offers up to $\$ 5,000$ worth of credit for companies based in South Africa and Singapore. ${ }^{40}$

(v) Alibaba Cloud offers a Create@Alibaba Cloud for SMEs, offering up to $\$ 10,000$ credit for up to 1 year, including one-on-one support in the form of cloud architects and tech support; marketing and co-branding opportunities; market entry assistance to the PRC; and other community activities such as workshops, conferences, and competitions. ${ }^{41}$

AWS. AWS Activate. https://aws.amazon.com/activate/

AWS. 2020. AWS Launches Activate Founders Package, Offering up to $\$ 1,000$ in Credits to Select Bootstrapped Startups. AWS News. 24 February.

3 AWS. AWS Activate Portfolio. https://aws.amazon.com/activate/portfolio/

Google. Google Cloud. https://cloud.google.com/free

Google. Google for Startups. https://startup.google.com/

Microsoft. Microsoft for Startups: Benefits. https://startups.microsoft.com/en-us/benefits/

40 Huawei Cloud. SMEs \& Start-Ups Program. https://intl.huaweicloud.com/en-us/activity/start-up/index0.html

41 Alibaba Cloud. The Program Package. https://www.alibabacloud.com/startup 


\section{RECOMMENDATIONS: HOW GOVERNMENTS CAN SUPPORT THEIR START-UPS WITH CONDUCIVE POLICIES}

Governments play a key role in addressing the barriers to cloud adoption and can encourage uptake among start-ups through conducive policies. Besides implementing policies that support the digital economy more generally, governments can take more targeted cloud-specific measures to increase awareness, which would both help create business opportunities for start-ups and increase long-term innovative capacity and competitiveness. The recommendations below reflect the holistic nature of supporting start-ups via cloud and the need to enable cloud adoption.

\section{A. Expand connectivity, digital identity solutions, and digital payment models.}

It is imperative for governments to consider the availability of baseline infrastructure and foundational elements for a digital economy, which enable the emergence of agile, resilient, and competitive tech start-ups, powered by cloud computing.

\section{Expand connectivity through building up network infrastructure.}

Given that internet access is still a major hurdle for many developing markets, building up telecommunications infrastructure to support populations in urban as well as more underserved rural markets will be important for start-ups to take advantage of cloud services, as well as for start-ups to help reach customers.

However, strong telecommunications networks, such as those with internet exchange points, do not, on their own, provide a solid footing for the emergence and growth of a digital economy. ${ }^{42}$ The full economic potential of a digital economy can only be leveraged with sufficient access to data storage and cloud computing resources that process the data flows. This includes ensuring access to data flows not just within countries, but across borders as well.

In the Philippines, the Department of Information and Communications Technology developed a National Broadband Plan (NBP) that is helping to increase connectivity across the country and promote affordability and speed. The NBP takes a multipronged approach to examining the legal and regulatory environment to propose measures that the Government of the Philippines can take to reform the telecommunications industry and promote investment, while also building up infrastructure itself. ${ }^{43}$ To this end, the department has been implementing a free Wi-Fi program in public places such as schools and municipal buildings and has worked on installing backbone infrastructure using dark fiber that supports the electrical grid. Though the NBP is still in the implementation process, the national

42 "An internet exchange point (IXP) is a physical location through which internet infrastructure companies such as internet service providers and content delivery networks connect with each other. These locations exist on the 'edge' of different networks, and allow network providers to share transit outside their own network. At its core, an IXP is essentially one or more physical locations containing network switches that route traffic between the different members' networks. Via various methods, these networks share the costs of maintaining the physical infrastructure and associated services. By having a presence inside of an IXP location, companies are able to shorten their path to the transit coming from other participating networks, thereby reducing latency, improving round-trip time, and potentially reducing costs." Source: Cloudfare. n.d. What is an Internet Exchange Point? | How do IXPs work?; and G.Z. Islam et al. 2020. Achieving Robust Global Bandwidth Along with Bypassing Geo-Restriction for Internet Users. Indonesian Journal of Electrical Engineering and Computer Science. 18(1): 112-123.

43 Government of the Philippines, Department of Information and Communications Technology. 2017. National Broadband Plan: Building Infostructures for a Digital Nation. 
average fixed broadband download speed increased from 7.91 megabits per second in July 2016 to 26.08 megabits per second in September 2020, indicating that while there is much room for improvement, the NBP framework has helped increase internet quality and accessibility. ${ }^{44}$

Indonesia, which has emerged as a producer of unicorn start-ups such as Gojek, Tokopedia, and Traveloka, has also embarked on similar initiatives to improve connectivity in hard-to-reach areas of the archipelagic country. In October 2019, the Ministry of Communication and Information Technology completed the Palapa Ring project, an ambitious initiative spanning 35,000 kilometers of undersea fiber optic cables and 21,000 kilometers of land cables. ${ }^{45}$ The completion of the project is meant to create digital economy opportunities for localities that previously had little to no internet access, while also enabling digital literacy and e-government services. The ministry's Telecommunication and Information Accessibility Agency is now also drafting a digital roadmap on connectivity infrastructure, focusing on developing the required ecosystem in rural areas to improve and increase access to health and other services. ${ }^{46}$ The roadmap is therefore expected to spur infrastructure development, enabling enterprises that are working to provide health care, financial services, and other vital services important for postCOVID-19 recovery.

\section{Implement digital identification solutions.}

Digital identity forms a foundational element for the provision of services that require identification, such as financial services, digital health solutions, and access to social security entitlements. As such, implementation of digital identification systems can simplify a wide range of online transactions and support the growth of start-ups, including in new market segments with customers who have not been serviced by traditional businesses.

Singapore's SingPass (Singapore Personal Access) is an example of a digital identification system that serves as the gateway to e-government services. It provides access to the services of more than 60 government agencies online as well as on mobile devices. ${ }^{47}$ In 2018 , the government announced the National Digital Identity initiative, which aimed to update and upgrade the capabilities of the SingPass so that citizens could access secure online transactions for e-government and private sector services. It features three main components: biometric elements, encryption, and open application program interfaces. ${ }^{48}$ The system has already launched a SingPass mobile app and Mylnfo, which manages a digital vault with citizen personal data, enabling more seamless online transactions by auto-filling forms. An extension of this is the SingPass Identity Verification, which allows companies to verify your identity without any transfer of your personal data to the company itself (using SingPass as a trusted verification entity). Through extending this to the private sector to auto-fill application forms, Mylnfo removes a known pain point in a typical user journey and adds a trusted layer to digital transactions, particularly useful for start-ups who need to win the trust of their new customers.

In a country where many people lack any form of formal identification, Digizen is working with ADB, in collaboration with MiBank and Women's Microbank, on a pilot program for Papua New Guinea to develop a trusted process by which identity documentation is done remotely (rather than having individuals travel many days to the city for this administrative process). Bank clients are issued a Digizen biometric e-identity card which is also a near-field communications smart card. This e-identity card

\footnotetext{
44 X. Gregorio. 2020. NTC Paints Rosier Picture of Internet Connectivity in Philippines at House Hearing. Phil Star Global. 5 November.

45 A. F. Medina. 2020. Indonesia's Palapa Ring: Bringing Connectivity to the Archipelago. ASEAN Briefing.

46 Government of Indonesia, Ministry of Communication and Information Technology. 2020. Managing Director of BAKTI Kominfo: Infrastructure of Health Care Facilities. 14 October.

47 Government of Singapore, Ministry of Finance. 2016. Fact Sheet: SingPass. 29 January.

48 NDI Developer and Partner Portal. https://www.ndi-api.gov.sg/
} 
can then be read with near-field communications-enabled devices, such as mobile phones and tablets, to allow users to open bank accounts and get access to finance. The project is particularly significant because it can be delivered when internet access is not always readily available, bears strong security standards with end-to-end encryption, and is secured with Public Key Infrastructure. ${ }^{49}$

Other countries in Asia and the Pacific are also in the process of implementing or have already implemented digital IDs to varying levels of success, including Indonesia, Malaysia, the Philippines, and Thailand. ${ }^{50}$

\section{Establish and promote digital payment models.}

A shift to e-payment models should be encouraged to promote safety, efficiency, and convenience; plug leakages; and help widen the net of financial inclusion. Digital payments help advance the evolution of the digital economy and facilitate the growth and innovation of a host of other financial technology services, many of which would naturally be using cloud technology.

In pursuit of the benefits presented by e-payments, many cash-reliant Asian countries are now making the shift to digital transactions through creating the necessary banking infrastructure and encouraging use of e-payments over cash.

The Philippines' central bank, Bangko Sentral ng Pilipinas (BSP), established the National Retail Payment System to increase the country's proportion of e-payments. The BSP established two automated clearing houses that facilitate e-payment transactions; the overall share of all payment transactions is likely to surpass $50 \%$ before mid-2023, which was its initial target. ${ }^{51}$

In Viet Nam, the State Bank of Vietnam amended their policies to allow banks to perform digital knowyour-customer due diligence checks for account opening and transactions, paving the way for banks and citizens to go digital for their banking needs. ${ }^{52}$

\section{B. Encourage educational institutions to teach cloud skills and to leverage cloud platforms for student projects and services.}

To address the issue of lack of awareness of cloud services, cloud technology should be presented early on in educational settings to promote familiarity and skills development. Because the private sector is best-placed to keep up with the changing demands of technology, governments can rely on private sector resources and knowledge to help bridge these awareness gaps.

- AWS runs the Educate program where teachers and students of all ages can sign up for free workshops and webinars and learn about different cloud careers. The program also assists institutions in supporting instructors and developing curricula to prepare students from high school, vocational schools, and universities in cloud skills. ${ }^{53}$

49 Digizen ID. Digital ID for Extreme Conditions. https://digizen.id/

50 C. Lago. 2019. Which Countries are Implementing Digital IDs in SE Asia? CIO. 4 January.

51 Bangko Sentral ng Pilipinas. n.d. Payments and Settlements - National Retail Payment System; and L. C. Chipongian. 2020. BSP's Target for e-Payment Will Come Sooner-Diokno. Manila Bulletin. 9 May.

52 Viet Nam Law and Legal Forum. 2020. Central Bank Allows eKYC for Online Opening of Payment Accounts. 7 July.

53 AWS. AWS Education. https://aws.amazon.com/education/awseducate/ 
These early introductions not only open pathways for young people to learn about cloud, but also allow them to develop in-demand and critical skills supporting start-up growth and development. As cloud usage increases and evolves among start-ups and traditional businesses gearing up for digital transformation, prospective employees who have existing cloud computing skills sets will have an advantage in the job market.

Governments may also encourage and broker direct partnerships where CSPs directly provide cloud services to educational institutions, and where students and teachers may be introduced to and grow familiar with cloud tools.

- The Google for Education program provides use of the G Suite cloud platform to educational institutions. ${ }^{54}$ This promotes familiarity with software-as-a-service from an accessible level to both students and educators, while also demonstrating how cloud technology is integral to everyday tasks. In addition, Google has programs to promote student learning of cloud skills, allow faculty to upskill their own cloud training, and help researchers use the cloud to further their research. ${ }^{55}$

- AWS has announced partnerships with seven higher education institutions in India to incorporate cloud-computing curricula as part of undergraduate degree and postgraduate diploma programs. ${ }^{56}$ In Australia, AWS has partnered with Swinburne University to establish Australia's first cloud degree program. ${ }^{57}$

\section{Partner directly with cloud service providers and their respective service providers.}

Start-ups are often looking for solutions to the unique problems of the markets in which they operate. Depending on the nature of the business, one consideration for start-ups would be to work with hyperscale CSPs that have a presence across multiple countries, with a local CSP, or a combination of the two. Start-ups need to find the right balance of resources to develop locally sensitive, context-aware products and services.

- For example, the AWS Partner Network has a presence throughout Asia and the Pacific region (Australia, the PRC, India, Indonesia, Japan, the Republic of Korea, Malaysia, New Zealand, and Singapore), providing start-ups with a diverse group of partner companies to help them formulate the right product for their market..$^{58}$

- Huawei runs a very specific SME \& Start-Ups program which offers support to start-ups located in Singapore and South Africa. ${ }^{59}$ In addition, the company launched a Huawei Seeds for the Future program, which has hosted students from Tajikistan to introduce cloud-computing technologies to them. ${ }^{60}$

- Alibaba's start-up program, Create@Alibaba Cloud, offers market entry assistance to start-ups looking to gain access into the market in PRC (footnote 41).

54 Google. Google for Education: G Suite for Education. https://edu.google.com/

55 Google. Google for Education: Programs. https://edu.google.com/programs/?modal_active=none

56 AWS. 2020. AWS Announces the Expansion of Cloud Computing Curricula to Seven Institutions in India. AWS Public Sector Blog. 13 July.

57 AWS. 2020. Swinburne University Launches Undergraduate Associate Degree in Cloud Technologies. AWS Public Sector Blog. 20 October.

58 AWS. AWS Partner Network. https://aws.amazon.com/partners/

59 Huawei Cloud. SMEs \& Start-Ups Program: Benefits for SMEs and Start-Ups. https://intl.huaweicloud.com/en-us/activity/ start-up/indexO.html

60 Huawei Cloud. Seeds for the Future Program in Tajikistan. https://www.huawei.com/en/sustainability/win-windevelopment/social-contribution/seeds-for-the-future/tajikistan 


\section{Encourage government agencies to revamp their data strategies and increase the use of cloud infrastructure and services, while strengthening the competitiveness of local start-ups.}

The strongest endorsement of supporting cloud for start-ups is to lead by example. In this manner, governments themselves can embrace cloud and adopt cloud solutions to serve as an example for businesses looking to move to the cloud and lead digital transformation. This also serves as an indicator to innovative ventures such as start-ups that governments are encouraging cloud usage.

Several governments around the world have already adopted "cloud-first" policies, which encourage the public sector to adopt cloud solutions to serve their ICT needs. This started first with the United States in 2010, ${ }^{61}$ and then the United Kingdom in 2013, ${ }^{62}$ followed closely by other governments including Australia, ${ }^{63}$ Bahrain, ${ }^{64}$ Japan, ${ }^{65}$ Malaysia, ${ }^{66}$ Saudi Arabia, ${ }^{67}$ and the Philippines. ${ }^{68}$ The Philippines recently amended its policy to further promote cloud usage for the legislative and judicial branches, while making cloud the de facto IT solution for executive branch government agencies. Some countries such as Indonesia and Viet Nam are exploring the adoption of cloud frameworks along with an increase in e-government services, while others such as Azerbaijan are working to build national data centers that will support their government's move to cloud. ${ }^{69}$

The Kingdom of Bahrain implemented their cloud-first policy on 14 June 2017 with a document stating guidance principles for the approach. ${ }^{70}$ It details how public agencies should consider cloud-computing solutions as a primary part of their IT planning and procurement. This will also positively influence Kuwait, as both countries signed a memorandum of understanding (MOU) on cloud computing in $2018 .^{71}$

While Azerbaijan does not have a cloud-first policy, it is starting its digital transformation journey via cloud-based e-government plans, ${ }^{72}$ and the development of a public sector e-government citizen services portal. ${ }^{73}$

\section{E. Develop regional agreements to open up regional data exchange and commerce to grow the market for tech start-ups.}

Start-ups are characterized in part by their ability to expand rapidly, resulting in start-ups with business units across multiple countries. To facilitate business expansion for tech start-ups and broaden potential markets, governments should promote cross-border data transfers through developing bilateral and multilateral agreements for regional data exchange and commerce.

\footnotetext{
J. McKendrick. 2010. US Government Adopts ‘Cloud-First' Policy. ZD Net. 30 November.

Government of the United Kingdom. 2017. Government Cloud First Policy. 3 February.

3 Government of Australia, Digital Transformation Agency. Secure Cloud Strategy. https://www.dta.gov.au/our-projects/ secure-cloud-strategy

64 Bahrain National Enterprise Architecture. Cloud-First Policy. http://www.nea.gov.bh/Cloud-First-Policy

65 D. Wyld. 2010. The Cloudy Future of Government IT: Cloud Computing and the Public Sector Around the World. International Journal of Web \& Semantic Technology. 1 (1). pp. 1-20.

66 The Government of Malaysia's Official Gateway. 1 GovCloud. https://www.malaysia.gov.my/portal/content/30097

67 Government of Saudi Arabia, Ministry of Communications and Information Technology. 2019. KSA Cloud First Policy. February.

68 Government of the Philippines, Department of Information and Communications Technology. 2020. DICT Releases Amended Cloud First Policy for Gov't Transition to “New Normal." 12 June.

69 Menafn Trend News Agency. 2020. Azerbaijan to Create 'Government-Cloud' National Data Center. 22 December.

70 Bahrain Information and eGovernment Authority. 2017. Cloud First Policy.

71 Trade Arabia Business News Information. 2018. Bahrain, Kuwait Ink Strategic Cloud Computing Deal. 6 October.

72 H. Luxford. 2014. Azerbaijan Moves to the Cloud. Data Centre Dynamics. 17 June.

73 Azerbaijani Service and Assessment Network. https://asan.gov.az/az
} 
Many of these agreements are currently in bilateral form, with Singapore emerging as a leader in forging these international connections. A key example is the Singapore-Australia Digital Economy Agreement, which aims to digitalize trade processes and facilitate cross-border business between the two countries. One MOU signed under this agreement is for data innovation to "provide access to data to promote the development of new products, services and digital solutions." "In addition, the agreement encourages cross-border data flows and prohibitions on data localization, further supporting the growth of tech start-ups moving into new markets or taking advantage of the services offered by hyperscale CSPs.

More specific to tech start-ups, Singapore has also established the Global Innovation Alliance through Enterprise Singapore and the Singapore Economic Development Board to establish international connections to help develop pathways for local start-ups. In 2019, Singapore signed an MOU with Quest Ventures and Saigon Innovation Hub, a government-backed agency intended to develop Ho Chi Minh City as a start-up and ICT hub, to provide bilateral assistance to Singapore start-ups that want to expand to Viet Nam and for Vietnamese start-ups looking to do the same in Singapore. ${ }^{75}$ Singapore has similar partnerships with local institutions in the PRC, India, Indonesia, Japan, and Thailand. ${ }^{76}$

Chile, New Zealand, and Singapore signed a Digital Economy Partnership Agreement on 12 June 2020 to establish basic rules to promote more opportunities to include more people, and particularly small businesses such as start-ups, in the global economy. ${ }^{77}$

In May 2018, the Council of Arab Economic Unity at the League of Arab States signed an MOU with the United Kingdom's Government Digital Services to cooperate in research and development in the fields of economy and digital transformation. ${ }^{78}$

At a sector level, central banks around the region have also signed bilateral agreements to promote crossborder cooperation and digital financial innovation, helping spur market expansion through e-payments, specifically boosting financial technology (fintech) and start-ups.

The Bangko Sentral ng Pilipinas (BSP) and the Monetary Authority of Singapore have agreed to work together on cross-border data transfer and information sharing, with a key provision to allow covered institutions to store and process data in any location so long as regulatory authorities have full and timely access to the data. ${ }^{79}$

The BSP has also signed an MOU with Bank Indonesia for a "more secure, efficient and reliable payment system, and to promote digital financial innovation," which is anticipated to enable crossborder payments beneficial to tech start-ups. ${ }^{80}$

In 2018, Kazakhstan's Astana Financial Services Authority, the Astana International Financial Centre Authority, and the Monetary Authority of Singapore signed a tripartite Cooperation Agreement that

\footnotetext{
74 Government of Singapore, Ministry of Trade and Industry. Singapore-Australia Digital Economy Agreement. https://www. mti.gov.sg/Improving-Trade/Digital-Economy-Agreements/The-Singapore-Australia-Digital-Economy-Agreement

75 M. Sagar. 2019. Singapore and Viet Nam to Collaborate to Boost Technology Start Ups. Open Gov. 19 July.

76 Enterprise Singapore. Startup Hub: Global Innovation Alliance. https://www.enterprisesg.gov.sg/industries/hub/startup/ global-innovation-alliance

77 Organization of American States. Digital Economy Partnership Agreement. http://www.sice.oas.org/TPD/DEPA/DEPA_e. asp

78 Daily News Egypt. 2018. MoU between CAEU, British Prime Minister to Digitally Support Arab Economy. 26 May.

79 L. C. Chipongian. 2020. BSP, Singapore, Working on Data Connectivity, Info Sharing. Manila Bulletin. 17 November.

80 L. Nantu. 2020. Indonesia, Philippines Central Bank Inks Deal on Payment Systems. The Insider Stories. 4 February.
} 
provides a framework for tripartite fintech innovation cooperation among their institutions. ${ }^{81}$ It will allow all three authorities to explore joint participation in projects, and information sharing.

The Dubai Financial Services Authority and Luxembourg's Commission de Surveillance du Secteur Financier signed an MOU in 2019 to enhance cooperation in fintech development, and other emerging trends, developments, and regulatory issues that relate to new technologies. ${ }^{82}$

\section{F. Support tech start-ups directly and support incubators, hubs, venture capital firms and accelerators through cloud-ready network infrastructure and targeted incentives.}

Governments can also work to nurture start-ups and encourage them to use cloud computing by providing direct cloud-related support to start-ups as well as to incubators, hubs, accelerators, and other tech communities. This could positively influence both cost and familiarity as barriers to cloud adoption among start-ups. In many cases, some of these support functions could be delivered in partnership with the private sector, such as through favorable programs encouraging angel investors and investment firms (such as tax incentives for such companies), or through other programs conducted in collaboration with private companies. Examples of such programs are:

(i) AWS Activate program, which provides funded and non-funded start-ups with cloud resources such as credits, training, and technical support (footnote 34);

(ii) Google Cloud, which has the Google Cloud for Start-Ups program to provide credits, community events, and training; 83 and

(iii) Microsoft for Start-Ups, which provides targeted support and access to different cloud technologies for start-up departments, including free credit and support. ${ }^{84}$

Direct support from CSPs can also help create and enable start-ups, but in many markets start-up facilitators, such as incubators and hubs, also exist to help provide more localized on-the-ground support to new companies. Both governments and the private sector should look to such communities as essential to the flourishing of a local tech and start-up scene, and thereby help with incubators, hubs, and accelerators.

In the Philippines, QBO is an innovation hub supported by the Department of Trade and Industry and the Department of Science and Technology that helps support local start-ups. In addition to an incubation program, QBO also hosts events, classes, and workshops to provide information and resources needed to address the problems faced by early-stage start-ups. ${ }^{85}$

Similarly, Impact Hub is a social enterprise in Phnom Penh, Cambodia that is part of a global network spanning more than 100 cities. Impact Hub works across business types but is focused on enabling sustainability and start-ups that have social impact. It has incubation and pre-incubation programs, and hosts workshops and online learning. ${ }^{86}$

\footnotetext{
Fintechnews Singapore. 2018. Singapore and Kazakhstan Signed an Agreement to Boost Fintech Innovations. 14 November. C. Hamblin. 2019. DFSA and CSSF Ink FinTech MoU. Compliance Matters. 2 December.

Google. Google Cloud: Startup Program. https://cloud.google.com/developers/startups

4 Microsoft. Microsoft for Startups. https://startups.microsoft.com/en-us/

5 QBO. About QBO. https://www.qbo.com.ph/about

86 Impact Hub Phnom Penh. About Impact Hub Phnom Penh. https://phnompenh.impacthub.net/about-us/
} 
Both QBO and Impact Hub have helped create and bring together local start-ups. Governments could consider further supporting these institutions through cloud skill development offers, or through partnering with CSPs to provide stronger curation of cloud resources that can be provided to incubated start-ups. Governments facilitating such support through partnerships, education, and making sure cloud-computing resources are available to start-ups, can foster not only a better understanding of cloud technology but also promote usage among the next generation of potential unicorns.

The Australian government has a support program for incubator companies to start-up in the country with an incubator grant. ${ }^{87}$ This grant provides new and existing incubators with funding to help start-ups develop the capabilities to succeed in international markets.

Singapore's Enterprise Singapore also provides various grants for start-ups, such as the Start-Up SG Founder grant for new entrepreneurs, and the Start-Up SG Tech grant which provides for early-stage funding to fast-track commercialization of technology solutions. ${ }^{88}$

\section{G. Support data privacy and cybersecurity policies that inspire public confidence in digital services.}

In some developing countries, foundational regulations to enable the digital economy, such as a data protection law and cybersecurity policy, have yet to be implemented. Governments should consider putting in place such regulations as they help increase public confidence in both government and private sector services because they assure adequate levels of oversight and protection.

The Philippines was a relatively early adopter of a data protection law through the passage of its Data Privacy Act of 2012. This law established the National Privacy Commission, which has launched investigations and acted on privacy violations. This commission's work helps assure that data protection provisions are complied with, while also elevating the Philippines' status as a regional leader in data protection. ${ }^{89}$

Governments should also seek to enable cross-border data transfer as a general matter, while ensuring proper protections for data privacy. Some countries continue to equate data localization with better security, even though in a cloud context, security is reliant on the specific measures that the customer decides to implement. For example, a customer may decide to share his account password with another person, who then breaches the customer's trust and absconds with a large sum of money. In this case, a better preventive security measure could not have been implemented, even if the data were stored within the country.

Indonesia's Government Regulation 71/2019 draft implementing regulation for private sector electronic service providers, for instance, requires that all activities to manage, store, or process data outside of Indonesian borders require approval from the data owner, which may be an onerous process for startups and other businesses to put in place. ${ }^{90}$

Rather than making data localization the rule for all data protection measures, countries should seek principles-based policy frameworks that prioritize adequate protection of customer data, based on the materiality of risk involved, rather than its location. Some possible solutions could include:

\footnotetext{
Government of Australia. 2021. Funding for Incubators to Assist Start-Ups to Succeed in International Markets. 12 May. 8 Enterprise Singapore. 2018. Grants. 17 August. https://www.enterprisesg.gov.sg/financial-assistance/grants.

89 Philippine National Privacy Commission. 2019. PH Joins APEC Privacy System. 20 September.

90 R. Yudha Triarianto et al. 2020. Key Points of Government Regulation No. 71 of 2019 on Organization of Electronic Systems and Transactions. SIP Law Firm. 6 August.
} 
(i) ensuring that all data is stored and transmitted in encrypted form, with strong security protections on the transmission mechanism;

(ii) working on providing a mechanism to pseudonymize data when dealing with customer data, which is a method of replacing or removing information in a data set that identifies an individual; and

(iii) developing a framework for data classification, which will allow governments to recognize different categories of data and apply different storage requirements based on their criticality and sensitivity. ${ }^{91}$

Otherwise, governments risk having their own digital economies limited by the inability of start-ups and other businesses to use cloud technology and to effectively utilize cross-border data flows.

\section{CONCLUSION}

The potential for start-ups to generate opportunities for economic growth can be expanded greatly with the use of cloud-computing technologies. As this report has demonstrated, start-ups face a number of barriers to using these technologies, particularly where government policies for infrastructure development and data governance are lagging behind. Resource limitations may also hamper start-ups exploring all aspects of cloud computing and how it could aid their business development.

Governments can pave the way to greater adoption and use of cloud computing by start-ups by ensuring that the foundational technologies underpinning the emergence and growth of a digital economy are in place. These include affordable access to digital connectivity (particularly mobile broadband), digital identity frameworks, digital payment systems, data protection regulation, international trade agreements, and a strong focus on science, technology, and engineering and mathematics education. Governments have a clear role in providing an enabling environment and in laying the groundwork for local, regional, and global growth of homegrown technology start-ups.

91 F. Simorjay. 2014. Data Classification for Cloud Readiness. Microsoft Trustworthy Computing. 


\section{REFERENCES}

Abudheen, S. 2020. 6 of the World's Top 11 Startup Ecosystems are Now in Asia Pacific: Startup Genome Report 2020. E27. 26 June.

Alibaba Cloud. Program Package. https://www.alibabacloud.com/startup

- - - n.d. PinMe. Alibaba Customers.

- - - n.d. Tokopedia. Alibaba Customers.

Amazon Web Services (AWS). 2020. AWS Announces the Expansion of Cloud Computing Curricula to Seven Institutions in India. AWS Public Sector Blog. 13 July.

- - 2020. AWS Launches Activate Founders Package, Offering up to $\$ 1,000$ in Credits to Select Bootstrapped Startups. AWS News. 24 February.

- - 2020. Ayopop Makes Bill Payment Easy with API on AWS. Amazon Solutions.

- - - 2020. Games24x7 Uses Machine Learning on AWS to Personalize the Gaming User Experience. Amazon Solutions.

- - - 2020. inVOID Deploys its Verification Products Four Times Faster with the Help of AWS Managed Services. Amazon Solutions.

- - - 2020. ShopBack Cuts Infrastructure Costs by 60\% with Amazon EC2 Spot Instances. Amazon Solutions.

_- - 2020. Singsound Turns to AWS to Handle Workload Spikes. Amazon Solutions.

- - - 2020. StoreHub Helps Food and Beverage Businesses in Malaysia Overcome Lockdowns. Amazon Solutions.

_-_. 2020. Swinburne University Launches Undergraduate Associate Degree in Cloud Technologies. AWS Public Sector Blog. 20 October.

- - - 2018. Halodoc Reduces Time-to-Market by 30\% Using AWS. Amazon Solutions.

_- - 2017. Chai Point Scales to Support the Sale of 150,000 Cups of Chai Daily with AWS. Amazon Solutions.

-_- 2017. Ucarer Case Study. Amazon Solutions.

- - 2015. iFlix Case Study. Amazon Solutions.

-_- n.d. Botsify Enhances Customer Experience with AWS. Amazon Solutions.

- - n.d. Kmong Achieves 30\% Higher Conversion with AWS. Amazon Solutions.

- - - n.d. Urbanbase Launches Services 20x Faster with AWS. Amazon Solutions. 
- - - AWS Activate. https://aws.amazon.com/activate/

- - - AWS Activate Portfolio. https://aws.amazon.com/activate/portfolio/

- - - AWS Education. https://aws.amazon.com/education/awseducate/

- - - AWS Partner Network. https://aws.amazon.com/partners/

- - - Building Applications with Serverless Architectures. https://aws.amazon.com/lambda/server less-architectures-learn-more/

- - - Security, Identity, and Compliance on AWS. https://aws.amazon.com/products/security/

- - - Shared Responsibility Model. https://aws.amazon.com/compliance/shared-responsibility -model/

Asia Cloud Computing Association. 2020. Cloud Readiness Index 2020.

Azerbaijani Service and Assessment Network. https://asan.gov.az/az

Bahrain Information and eGovernment Authority. 2017. Cloud First Policy.

Bahrain National Enterprise Architecture. Cloud-First Policy. http://www.nea.gov.bh/Cloud-First-Policy

Bangko Sentral ng Pilipinas. n.d. Payments and Settlements - National Retail Payment System.

Blank, S. 2010. What's A Startup? First Principles. Steve Blank Blog. 25 January.

Bloomquist, D. 2014. Disrupting the Traditional VC Model: VC Adaptations for Seed Investments. Kauffman Fellows. 11 June.

Chen, J. 2020. Unicorn. Investopedia. 31 March.

Christensson, P. 2017. Latency. Tech Terms. 3 March.

Chipongian, L. C. 2020. BSP, Singapore, Working on Data Connectivity, Info Sharing. Manila Bulletin. 17 November.

Chipongian, L. C. 2020. BSP's Target for e-Payment Will Come Sooner-Diokno. Manila Bulletin. 9 May.

Cloudfare. n.d. What is an Internet Exchange Point? | How do IXPs work?

Daily News Egypt. 2018. MoU between CAEU, British Prime Minister to Digitally Support Arab Economy. 26 May.

Digizen ID. Digital ID for Extreme Conditions. https://digizen.id/

Docker. n.d. What is a Container?

Enterprise Singapore. 2018. Grants. 17 August. https://www.enterprisesg.gov.sg/financial-assistance/ grants 
-_- Startup Hub: Global Innovation Alliance. https://www.enterprisesg.gov.sg/industries/hub/ startup/global-innovation-alliance

Expedient. Data Center Build vs Buy Calculator. https://expedient.com/knowledgebase/tools-and -calculators/data-center-build-vs-buy-calculator/

Fintechnews Singapore. 2018. Singapore and Kazakhstan Signed an Agreement to Boost Fintech Innovations. 14 November.

Google, Temasek, and Bain \& Company. 2020.e-Conomy SEA 2020.

Google. n.d. AgroStar: Small Farms in India Getting Big Help from the Cloud. Google Cloud Customers.

_- - n.d. Kata.ai: Creating Natural Language Processing Solutions to Serve 200 million+ Indonesians. Google Cloud Customers.

- - - n.d. Traveloka: Turns to Google Cloud Platform for Powerful Big Data Analytics. Google Cloud.

- — Google Cloud. https://cloud.google.com/free

-——. Google for Education: G Suite for Education. https://edu.google.com/

- - - Google for Education: Programs. https://edu.google.com/programs/?modal_active=none

- - - Google for Startups. https://startup.google.com/

- - - Startup Program. https://cloud.google.com/developers/startups

Government of Australia. Funding for Incubators to Assist Start-Ups to Succeed in International Markets.

Government of Australia, Digital Transformation Agency. Secure Cloud Strategy. https://www.dta.gov .au/our-projects/secure-cloud-strategy

Government of Indonesia, Ministry of Communication and Information Technology. 2020. Managing Director of BAKTI Kominfo: Infrastructure of Health Care Facilities. 14 October.

Government of Malaysia's Official Gateway. 1 GovCloud. https://www.malaysia.gov.my/portal/content/ 30097

Government of the Philippines, Department of Information and Communications Technology. 2020. DICT Releases Amended Cloud First Policy for Gov’t Transition to “New Normal.” 12 June.

-_- 2017. National Broadband Plan: Building Infostructures for a Digital Nation.

Government of Saudi Arabia, Ministry of Communications and Information Technology. 2019. KSA Cloud First Policy. February.

Government of Singapore, Ministry of Finance. 2016. Fact Sheet: SingPass. 29 January.

Government of Singapore, Ministry of Trade and Industry. Singapore-Australia Digital Economy Agreement. https://www.mti.gov.sg/Improving-Trade/Digital-Economy-Agreements/The-Singapore-Aus tralia-Digital-Economy-Agreement 
Government of the United Kingdom. 2017. Government Cloud First Policy. 3 February.

Gregorio, X. 2020. NTC Paints Rosier Picture of Internet Connectivity in Philippines at House Hearing. Phil Star Global. 5 November.

Hamblin, C. 2019. DFSA and CSSF Ink FinTech MoU. Compliance Matters. 2 December.

Huawei Cloud. SMEs \& Start-Ups Program. https://intl.huaweicloud.com/en-us/activity/start-up/ indexO.html

Huawei Cloud. Benefits for SMEs and Start-Ups. https://intl.huaweicloud.com/en-us/activity/start-up/ indexO.html

Huawei Cloud. Seeds for the Future Program in Tajikistan. https://www.huawei.com/en/sustainability/ win-win-development/social-contribution/seeds-for-the-future/tajikistan

Husar, A. 2020. Fostering Resilient Start-Up Ecosystems in the New Normal. Development Asia. 4 September.

Impact Hub Phnom Penh. About Impact Hub Phnom Penh. https://phnompenh.impacthub.net/about-us/ Islam, G.Z. et al. 2020. Achieving Robust Global Bandwidth Along with Bypassing Geo-Restriction for Internet Users. Indonesian Journal of Electrical Engineering and Computer Science. 18 (1).

Lago, C. 2019. Which Countries are Implementing Digital IDs in SE Asia? CIO. 4 January.

Luxford, H. 2014. Azerbaijan Moves to the Cloud. Data Centre Dynamics. 17 June.

McKendrick, J. 2010. US Government Adopts ‘Cloud-First’ Policy. ZD Net. 30 November.

Medina, A.F. 2020. Indonesia's Palapa Ring: Bringing Connectivity to the Archipelago. ASEAN Briefing.

Mell, P. and T. Grance. 2011. The National Institute of Standards and Technology Definition of Cloud Computing: Recommendations.

Menafn Trend News Agency. 2020. Azerbaijan to Create 'Government-Cloud' National Data Center. 22 December.

Microsoft. 2020. Tech Startup Uses Azure Cognitive Services to Improve Advertising for Local Businesses. Microsoft Customer Stories. 10 August.

-_- 2019. Startup Uses Microsoft Kaizala to Empower Indonesian Retailers to Achieve More. Microsoft Customer Stories. 6 November.

- - Benefits: Microsoft for Startups. https://startups.microsoft.com/en-us/benefits/

- - Microsoft for Startups. https://startups.microsoft.com/en-us/

Nantu, L. 2020. Indonesia, Philippines Central Bank Inks Deal on Payment Systems. The Insider Stories. 4 February.

NDI Developer and Partner Portal. https://www.ndi-api.gov.sg/ 
Organization of American States. Digital Economy Partnership Agreement. http://www.sice.oas.org/ TPD/DEPA/DEPA_e.ASP

Philippine National Privacy Commission. 2019. PH joins APEC Privacy System. 20 September.

QBO. About QBO. https://www.qbo.com.ph/about

Sagar, M. 2019. Singapore and Viet Nam to Collaborate to Boost Technology Start Ups. Open Gov. 19 July.

Schneider Electric. Data Center Capital Cost Calculator. https:/www.se.com/ww/en/work/solutions/ system/s1/data-center-and-network-systems/trade-off-tools/data-center-capital-cost-calculator/

Simorjay, F. 2014. Data Classification for Cloud Readiness. Microsoft Trustworthy Computing.

Tech in Asia ID. 2019. How Tokopedia Guarantees its Platform Uptime. Youtube. 9 December.

-_- 2019. How Cloud Computing Helps Traveloka Scale its Product Delivery. Youtube.

25 November.

Trade Arabia Business News Information. 2018. Bahrain, Kuwait Ink Strategic Cloud Computing Deal. 6 October.

Viet Nam Law and Legal Forum. 2020. Central Bank Allows eKYC for Online Opening of Payment Accounts. 7 July.

Yudha Triarianto, R. et al. 2020. Key Points of Government Regulation No. 71 of 2019 on Organization of Electronic Systems and Transactions. SIP Law Firm. 6 August.

Wyld, D. 2010. The Cloudy Future of Government IT: Cloud Computing and the Public Sector Around the World. International Journal of Web \& Semantic Technology. 1 (1). 



\section{Cloud Computing as a Key Enabler for Tech Start-Ups across Asia and the Pacific}

New enterprises that produce digital solutions for businesses, public institutions, civil society, and consumers play a vital role in shaping digital economies. These dynamic start-ups most effectively integrate leading talent and sources of capital. They are driven by an urgency to succeed quickly-if they do not, they will then seek to deploy skills and resources more effectively. Governments need to establish or refine policies and mechanisms that foster vibrant start-up ecosystems, enabled by foundational technologies such as cloud computing. This paper provides an overview of the opportunities and challenges involved and suggests how policymakers can help start-ups make the most of cloud-computing technologies.

\section{About the Asian Development Bank}

ADB is committed to achieving a prosperous, inclusive, resilient, and sustainable Asia and the Pacific, while sustaining its efforts to eradicate extreme poverty. Established in 1966, it is owned by 68 members -49 from the region. Its main instruments for helping its developing member countries are policy dialogue, loans, equity investments, guarantees, grants, and technical assistance. 